\title{
Factors Influencing Adherence to Training Programs in Gyms in the Northern Region of Santa Catarina, Brazil
}

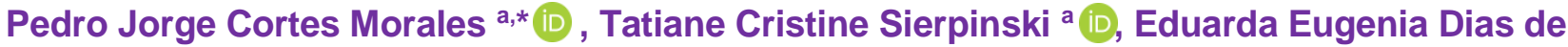 Jesus ${ }^{a}$ (D), Carlos Henrique Cenci de Oliveira ${ }^{a}{ }^{(D}$, Ricardo Clemente Rosa ${ }^{a}$ iD, Fabricio Faitarone Brasilino a}

a University of the Region of Joinville - UNIVILLE, Santa Catarina, Brazil.

*Corresponding author Ph: +55 (47) 99974-0989; Email: pedromorall@gmail.com

DOI: https://doi.org/10.34256/ijpefs2125

Received: 15-03-2021, Revised: 19-04-2021; Accepted: 25-04-2021; Published: 07-05-2021

Abstract: Objective: Identify the factors that influence the adherence of Resisted Training programs in gyms located in the city of Guaratuba, Paraná/BR. Methodology: The design of the present study is cross-sectional. A total of 100 Resisted Training practitioners of both genders, aged between 18 and 75 years, participated in the research. The location for data collection included four gyms located in the city of Guaratuba-PR. Considering the nature of the research, it was chosen to apply a questionnaire adapted from Morales (2002), composed of opened and closed-ended questions. The instrument was composed with exposure variables of sociodemographic, economic, environmental factors, self-perception of lifestyle and health, stress levels indicators and physical activity. The $S P S S \& 16.0$ program was used for statistical treatment. Considering the non-normality of the data distribution through the Kolmogorov-Smirnov test, Spearman's correlation test was used and values of $\mathrm{p}<0.05$ were considered significant. Results: The present study showed three significant moderate correlations, demonstrating a joint variation of tobacco use with alcohol $(0.655$ with $\mathrm{p}$-value $<0.05)$, intake of high alcoholic beverages over others $(0.802$ with $p$-value $<0.05)$, and men's weekly workload $(0.62$ with $p$-value $<0.05)$. Conclusion: According to the obtained data, it's possible to conclude through the significant moderate correlations, that the sociodemographic aspects and the identification of some behavioral risk factors related to the use of tobacco and alcoholic beverages, can influence the adherence to the training programs in gyms.

Keywords: Adherence, Resisted Training, Health, Life quality

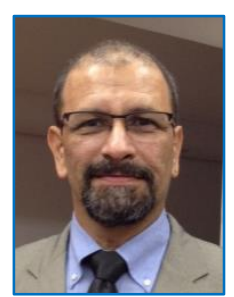

Pedro Jorge Cortes Morales completed a Doctoral Course in Educational Sciences at the University of Jaén in Spain. Currently pursuing a Doctorate in Health and Environment from the University of Joinville UNIVILLE (SC) in the area of physical activity and health. He has a master's degree in the area of physical education and health from the Federal University of Santa Catarina - UFSC (SC). He currently coordinates the physical education courses at Univille and the research group in motion - RGIM.

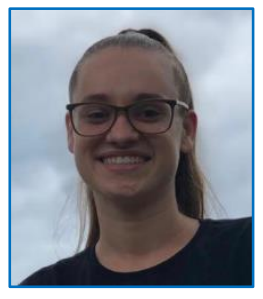

Tatiane Cristine Sierpinski is a student of the Physical Education course at Univille University (SC). Participates in the research group in motion - RGIM with lines of research related to body practices, health and quality of life. Trainee in the areas of weight training, public health and physical activity for special populations.

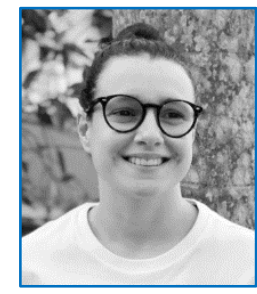

Eduarda Eugenia Dias de Jesus is a student of the Physical Education course at Univille University (SC). Participates in the research group in motion - RGIM with lines of research related to body practices, health and quality of life. He has experience in child swimming as an extension worker at Univille University (SC). It is monitor of the discipline of kinesis and biomechanics.

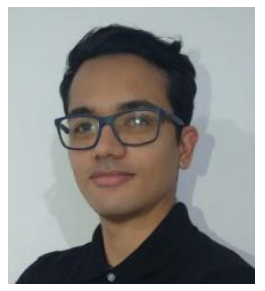

Carlos Henrique Cenci de Oliveira - Graduated in Physical Education at the University of the Region of Joinville - Univille (SC). Acts as a teacher and manager of the Guga Tennis School in Rio 
Grande do Sul - Joinville Tennis - SC. Fitness professional. Invited researcher of the research group in motion - RGIM.

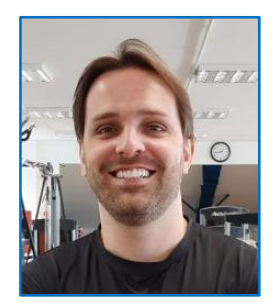

Ricardo Clemente Rosa - Studying the master's degree in health and environment at Univille University (SC) with a scholarship from the institutional program to support research for scientific training in graduate studies (PIC PG, Brazil). He has a degree in physical education from Univille University (SC) and a specialization in physiology and kinesiology of physical activity and health from Gama Filho University (RJ). He is currently technical responsible for the Univille gym and a member of the research group in motion - RGIM.

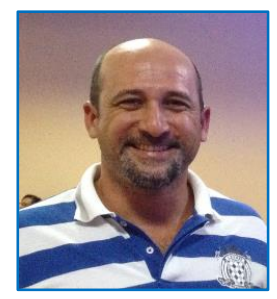

Fabrício Faitarone Brasilino Graduated in Physical Education from the University of the Region of Joinville - Univille (SC). Specialization in Personal Training and Sports Training by CEFID/Udesc (SC). Master's in health and Environment from the UNIVILLE University (SC). Professor at the School of First Aid Training Vital Force (PR). International Certification in Basic Life Support by the American Heart Association (AHA2019). second leader of the research group in motion RGIM.

\section{Introduction}

The regular practice of physical exercise is one of the main pillars for maintaining physical and mental health, contributing positively to a consistent life quality. For this reason, the repercussion of its benefits can prevent by $30 \%$ the number of deaths in the world [1]. Thus, the benefits of physical exercise are associated with a longer period of health, fundamental for an adequate and safe longevity [2].

According to Pereira and Gama [3], for effective results, physical exercise must be performed on a regular basis, planned, systematized and supervised by a trained professional, in order to increase the benefits to practitioners with quality.

Thus, among a wide variety of exercises, such as: walking, team sports, water sports, aerobic training, among others, is Resisted Training (RT). The RT is one of the most common modalities, given its popularity and accessibility [4], and can be defined as an exercise in which the body musculature encounters an opposing force/resistance. Therefore, it can be performed with the help of machines, free weights, rubber band or body weight.
According to Nestler et al. [5], it is possible to consider RT a valuable tool for increasing musculoskeletal fitness, muscle mass, strength levels and bone mineral density. In view of the adaptations, the referred modality has been the target of recommendations for different population groups [6].

The motivational factors for choosing to join an RT program can be both intrinsic and extrinsic. Therefore, adherence can vary among several aspects, such as: age, gender, socioeconomic level, education level, individual's health, stress level, importance given to physical activity, company, comfortable environment, among many other reasons $[7,8]$.

Because of this, this research aimed to identify the factors that influence the adherence of RT programs in gyms located in the city of Guaratuba, Paraná/BR.

\section{Materials and Methods}

The design of the present study is crosssectional. A total of 100 RT practitioners of both genders, aged between 18 and 75 years, participated in the research. As an inclusion criterion, it was accepted individuals with at least 6 months of RT exposure and no apparent lesions. The location for data collection included six gyms located in the city of Guaratuba-PR. The choice of participants was made by personal invitation, constituting a convenience sampling.

Participants chose to perform resistance / weight training exercises, usually using machines, free weights, elastics, or their own body weight. At first, they went through an anamnesis and received, during their training programs, instructions according to the desired objective.

Considering the nature of the research, it was decided to apply an adapted questionnaire from Morales (2002) [9], containing opened and closedended questions to measure responses on adherence to the RT practice. The instrument was composed with exposure variables of sociodemographic, economics, environmental factors, self-perception of lifestyle and health, stress levels indicators and physical activity.

The distribution method used was virtual (Google Forms $\AA$ ) through social network apps such as WhatsApp $^{\circledR}$ and Instagram $^{\circledR}$, and face-to-face for those who were available. Thus, to respond the form, it was necessary to consent the participation by means of the Informed Consent Form (ICF). This document needed 
approximately 10 minutes to be completed, being quick to read and understand.

The Microsoft Excel\& for Windows $\mathbb{R} 10$ program was used to organize the data, to be subsequently transferred and analyzed using the Statistical Package for the Social Sciences - IBM SPSS $\mathbb{R}$ 16.0 program. Considering the non-normality of the data distribution through the Kolmogorov-Smirnov test, Spearman's correlation test was used and values of $\mathrm{p}<0.05$ were considered significant.

This study has the favorable opinion of the Research Ethics Committee of the University of the Region of Joinville/SC - REC - UNIVILLE, according to the National Health Council for research with human beings, under number 3.276.170.

\section{Results}

According to the obtained data, it was possible to verify in the sample characterization, a mean age of $36.28 \pm 12.78$ years among the participants, in which 50 (50\%) were men and 50 (50\%) were women.

When selecting the six gyms, it is noted that the average monthly fee was $\mathrm{R} \$ 72.98$ (reais), with a minimum value of $R \$ 60.00$ and a maximum of $\mathrm{R} \$ 109.90$.

Table 1 shows the results regarding marital status, occupation, profession and weekly workload.

Table 1 Sociodemographic Characteristics of the sample

\begin{tabular}{|l|l|l|}
\hline \multicolumn{2}{|l|}{ \% } & N \\
\hline Marital Status & 32 & 32 \\
\hline Mingle & 56 & 56 \\
\hline Divorced & 7 & 7 \\
\hline Widowed/Others & 5 & 5 \\
\hline Occupation & \multicolumn{2}{l|}{} \\
\hline Currently Working & 80 & 80 \\
\hline Currently not working & 18 & 18 \\
\hline Did not answer & 2 & 2 \\
\hline Profession & \multicolumn{2}{|l|}{} \\
\hline Entrepreneurs & 15 & 15 \\
\hline Merchants & 12 & 12 \\
\hline Healthcare Professionals & 10 & 10 \\
\hline Public Employees & 10 & 10 \\
\hline Administration and Accounting & 9 & 9 \\
\hline Others & 44 & 44 \\
\hline Weekly workload & 15 & 12 \\
\hline 20 hours & \multicolumn{2}{|l}{} \\
\hline
\end{tabular}

\begin{tabular}{|l|l|l|}
\hline $\mathbf{3 0}$ hours & 20 & 16 \\
\hline $\mathbf{4 0}$ hours & 32.5 & 26 \\
\hline More then 40 hours & 32.7 & 27 \\
\hline Did not answer or do not work & 23.7 & 19 \\
\hline
\end{tabular}

The perception of health and stress level, as well as the current health complaints is reported in Table 2.

Given this, the participants were asked about their distance/location ratio and how they travel this route. It was possible to verify that $70 \%$ of the practitioners live up to 1 kilometer away from the gym, and the other $30 \%$ live 1 to 2.5 kilometers away. On the way to the gym, $48 \%$ go by foot, $38 \%$ by bicycle and $10 \%$ by car or motorcycle, proving the ease of access in relation to the means of transportation used by the participants.

It was also asked about the participants' knowledge regarding the benefits that physical exercise can provide to those who practice it. Two main benefits were asked, in which: $52 \%$ chose wellbeing and tranquility as their first option, followed by improvement in physical conditioning with $11 \%$; as a second option, improvement in physical conditioning with $36 \%$, lower risk of heart disease with $13 \%$, improvement in body aesthetics with $11 \%$ and selfconfidence with $9 \%$.

Table 4 shows main reasons why participants seek exercise programs, reasons for adherence and continuity to training.

Through Spearman's correlation analysis, it was possible to observe that there is, overall, a moderate correlation between tobacco uses with alcohol (0.655 with $p$-value $<0.05)$ regardless of gender, and among alcoholic beverages a strong correlation $(0.802$ with $p$-value $<0.05)$ for those with more alcohol content than the others. Women ingest more distilled spirits than men (0.834 with pvalue $<0.05$ ) with wine being their second preference.

Men showed a moderate correlation on weekly workload of 0.62 with $p$-value $<0.05$. The other correlations were not significant. 
Table 2 Perception of the sample

\begin{tabular}{|c|c|c|c|c|}
\hline & $\%$ & $\mathbf{N}$ & Men & Women \\
\hline \multicolumn{5}{|l|}{ Preception of health level } \\
\hline Excellent & 37 & 37 & 19 & 18 \\
\hline Good & 56 & 56 & 25 & 31 \\
\hline Regular & 7 & 7 & 6 & 1 \\
\hline \multicolumn{5}{|l|}{ Perception of Strees Level } \\
\hline Rarety Stressed & 35 & 35 & 18 & 17 \\
\hline Sometimes Stressed & 47 & 47 & 24 & 23 \\
\hline Almost always Stressed & 17 & 17 & 8 & 9 \\
\hline Excessively Stressed & 1 & 1 & 0 & 1 \\
\hline \multicolumn{5}{|l|}{ Current health complaints } \\
\hline Back pain & 24 & 24 & - & - \\
\hline Chronic pain & 18 & 18 & - & - \\
\hline Chronic diseases & 13 & 13 & - & - \\
\hline Joint problems & 11 & 11 & - & - \\
\hline Other & 34 & 34 & - & - \\
\hline
\end{tabular}

Table 3 Reasons for choosing the gym

\begin{tabular}{|c|c|c|}
\hline & $\%$ & $\mathbf{N}$ \\
\hline \multicolumn{3}{|l|}{ Reasons } \\
\hline Infrastructure & 11 & 11 \\
\hline Location & 9 & 9 \\
\hline Work offered by professionals & 6 & 6 \\
\hline others & 74 & 74 \\
\hline
\end{tabular}

Table 4 Sample motivations

\begin{tabular}{|c|c|c|}
\hline & $\%$ & $\mathbf{N}$ \\
\hline \multicolumn{3}{|c|}{ Reasons why they seek exercise programs } \\
\hline Health Preservation & 54.3 & 52 \\
\hline Practice enjoyment & 37.0 & 34 \\
\hline Keeping your baby defined & 35.1 & 31 \\
\hline \multicolumn{3}{|l|}{ other } \\
\hline \multicolumn{3}{|l|}{ Reasons for adherence } \\
\hline \multicolumn{3}{|l|}{ Main reason } \\
\hline Health & 41.6 & 40 \\
\hline Self-motivation & 16.5 & 16 \\
\hline \multicolumn{3}{|l|}{ Second reason } \\
\hline Well-being & 14.5 & 14 \\
\hline Aesthetics & 14.5 & 14 \\
\hline Results & 13.6 & 13 \\
\hline Health & 13.6 & 13 \\
\hline \multicolumn{3}{|l|}{ Reasons to Continue } \\
\hline Goals achived & 49.1 & 47 \\
\hline Enjoyment & 44.4 & 42 \\
\hline Health improvement & 42.5 & 40 \\
\hline Self-motivation & 22.3 & 21 \\
\hline Pursuit of the ideal body & 18.0 & 16 \\
\hline
\end{tabular}




\section{Discussion}

It is of global knowledge the benefits acquired by the regular practice of physical activity, thus, in order to obtain such improvements, it's necessary to initiate and adhere to the training. Therefore, the present study sought to identify the factors that influence the adherence of RT practitioners.

Initially, according to the findings regarding the gym's monthly fee and the sociodemographic characteristics, it is possible to infer the existence of financial stability, considering that $80 \%$ of the sample was inserted in the labor market, with a predominance of more than 40 hours of work per week, and being mostly composed of entrepreneurs.

The strength of this argument becomes even stronger when noticing a significant moderate correlation $(0.62$ with $p$-value $<0.05)$ on the men's part in this sample on the weekly workload.

This factor may be related to both the initiation and the permanence in training programs in gyms, indicating that this group has capital to afford the expenses related to this modality, since the monthly fees are accessible.

In this sense, the study by Jesus et al. [10] obtained a sample of 88 individuals from a gym in Joinville, Santa Catarina/BR, of both genders and aged between 18 and 48 years. The results demonstrated that the weekly workload for 34 participants was over 40 hours and for 33 it was 40 hours a week. The same study contrasts with the study by Peixoto and Cruz [11], in which $30 \%$ are employees of private companies and only $5 \%$ are entrepreneurs.

In the study by Batista et al. [12], 203 exercise practitioners were analyzed to identify the main adherence factors for training. Thus, the study identified that sociodemographic aspects influence adherence to physical exercise.

Esteves et al. [13] points out that the main causes for poor adherence to the training program were lack of time, distance, lack of motivation, increased working hours and unqualified professional service. Estimating that the value / price of the monthly fee is not always a reason for dropping out, becoming the least relevant factor in this regard [14, $15,16]$.

When checking the results corresponding to lifestyle and health, the participants showed a high rate of health perception (56\% "good" and 37\% "excellent"). Moreover, it was possible to identify a low stress level ( $47 \%$ "sometimes stressed"), indicating possible benefits caused by the RT practice.

In the study by Jesus et al. [10], regarding stress, 27 men and 19 women reported being sometimes stressed and living reasonably well.

In view of this, for the participants the main reason for the adherence of the training was health $(41 \%)$. The present study results corroborate with the research of Silva Filho et al. [17], which showed that the clients' greatest motivation for adherence to RT was health $(37.5 \%)$, enjoyment $(36.7 \%)$, followed by aesthetics (34.6\%).

According to Liz and Andrade [16], the reasons for joining RT were the sense of well-being, seeking to improved health, body aesthetics and socialization.

It is important to point out that location/distance has a preponderant influence on the enrollment in RT programs, since $70 \%$ of the participants lived $1 \mathrm{~km}$ away from the gym. Consequently, going by foot was predominant (48\%), confirming the ease of access to the training site. These findings corroborate with the study by Gonçalves, Bicalho and Noce [18] in which it is reported that the ease of access to the gym is provided by location, distance and means of transportation.

The survey also evidenced the practitioners' knowledge regarding the benefits provided by physical exercise. Therefore, the answers "well-being and tranquility" (52\%) prevailed, followed by "improvement of physical conditioning" (11\%).

Suggesting in this case, two other reasons that influence adherence to training programs in gyms. In the study by Jesus et al. [10], the benefits provided by regular practice were, in the first alternative, "wellbeing and tranquility" ( $n=37)$ and right after that, as the second alternative, "physical conditioning" $(n=28)$.

In the study by Peixoto and Cruz (11), the results about the benefits that RT brings to everyone were: improvement of physical conditioning (50\%), improvement of body aesthetics (34\%), fat loss (21\%), improvement of appearance (19\%), well-being and tranquility $(11 \%)$, and resistance to fatigue (10\%).

The reason for continuing training found in this study, was regarding the goals achieved (24\%). This result corroborates with the study of Peixoto and Cruz 
[11], in which it was found that the main reason for staying in the RT program was goals achieved (44\%). Similarly, in the study by Silva Filho et al. [17] it was observed that the main reasons for clients' permanence was achieving results (44.9\%) and professional competence (25\%).

Furthermore, the present study showed significant moderate correlations demonstrating a joint variation of tobacco use with alcohol ( 0.655 with $\mathrm{p}$ value $<0.05)$, and alcoholic beverages of higher alcohol content than others $(0.802$ with $p$-value $<0.05)$.

By means of the degree of relationship observed in the variables mentioned, it is possible to identify some behavioral risk factors related to health, which may have influenced the search for protective measures, as in the case of this study, the enrollment in RT programs.

Lately, alcoholic beverages have produced large amounts of consumption by the population [19]. Reducing alcohol intake and engaging in physical activity is an excellent way to prevent diseases [20].

The lack of life quality can be influenced using alcohol and/or tobacco, which interfere with health maintenance. Those who do not use these substances are able to have better satisfaction levels with their health and the environment [21].

In general, in the gym environment, the target audience does not make use of tobacco, but it is necessary to mention that, even in small number, tobacco does not go well with physical activity, because it can cause many harms, such as those associated with non-transmissible chronic diseases.

\section{Conclusion}

In accordance with the obtained data, it's possible to conclude through the significant moderate correlations found in this study, that the sociodemographic aspects and the identification of some behavioral risk factors related to the use of tobacco and alcoholic beverages, can influence the adherence to training programs in gyms.

Despite the other correlations not showing significance, it's observed through the descriptive statistics, that the search for life quality by means of health, well-being and tranquility, improvement in physical conditioning and ease of access to the modality, led the ranking of the main reasons for joining gyms among those who practice RT in the city of Guaratuba-PR.

It's also necessary to mention that the results obtained are limited by the type of choice of the population and its representativeness, although the data was collected in four different places in the city.

\section{References}

[1] R. L. de Mello, E. K. Ribeiro, J. Okuyama, (In) atividade física e comportamento sedentário: terminologia, conceitos e riscos associados, Caderno Intersaberes, 9 (2020) 59-68.

[2] G. N. Ruegsegger, F. W. Booth, Health benefits of exercise, Cold Spring Harbor perspectives in medicine, 8 (2018) 1-16. [DOI] [PubMed]

[3] E. S. Pereira, E. F. Gama, Imagem corporal da mulher praticante de exercício físico, HU Revista, 43 (2017) 5-11. [DOI]

[4] E. Aartolahti, E. Lönnroos, S. Hartikainen, A. Häkkinen, Long-term strength and balance training in prevention of decline in muscle strength and mobility in older adults, Aging clinical and experimental research, $325(2020)$ 9-66. [DOI] [PubMed]

[5] K. Nestler, A. Witzki, U. Rohde, T. Rüther, K. A. Tofaute, D. Leyk, Strength Training for Women as a Vehicle for Health Promotion at Work: A Systematic Literature Review, Deutsches Aerzteblatt International, 114 (2017) 439-446. [DOI] [PubMed]

[6] L. Baldissera, D. L. Machado, L. G. Alves, D. Faleiro, P. Zawadzki, (2017) Benefícios percebidos por praticantes de musculação para a saúde, estilo de vida e qualidade de vida. Unoesc \& Ciência-ACBS, 8 (2) 117-124.

[7] L.L. Vieira, V. Oliveira de, A.A. Machado, I.W. Tertuliano, Reasons for adherence and abandonment of physical activity, Manual Therapy, Posturology \& Rehabilitation Journal, 16 (2020) 1-5. [DOI]

[8] G. L. Stonerock, J.A. Blumenthal, Role of Counseling to Promote Adherence in Healthy Lifestyle Medicine: Strategies to Improve Exercise Adherence and Enhance Physical Activity, Progress in cardiovascular diseases, 59 (2014) 455-62. [DOI]

[9] P.J.C. Morales, (2002) Iniciação, aderência e 
abandono nos programas de exercícios físicos oferecidos por academias de ginástica na região de Joinville, Universidade Federal de Santa Catarina, Centro de Desportos, Florianópolis, (UFSC), 1-113

[10] E.E.D. Jesus, R.C. Rosa, I. Rosa, F.F. Brasilino, P.J.C. Morales, A influencia da atividade fisica na melhora da qualidade de vida, FIEP Bulletin, 91 (2021) 137-146. [DOI]

[11] D. H. C. Peixoto, R. W. de Sousa Cruz, Motivos Estimulantes À Prática De Musculação Em Uma Academia De João Pessoa-Paraíba, Diálogos em Saúde, 1 (2019) 27-45.

[12] R.P.R. Batista, G.L.M. Freire, R.M. Silva da, Souza W de, Silva BS dos $S$, et al. Fatores de motivação de praticantes de exercício físico da cidade de Petrolina-PE: um estudo comparativo, Psicol e Saúde em Debate, 6 (2020) 49-61. [DOI]

[13] D. Esteves, S.Vieira, R. Brás, K. O'Hara, P. Pinheiro, Nível de atividade física e hábitos de vida saudável de universitários portugueses, Revista Iberoamericana de Psicología del Ejercicio y el Deporte, 12 (2017) 261-270. [DOI]

[14] André Luiz Galvim, Isabela Martins Oliveira, Tatiane Vieira Martins, L. Vieira, N. Cerri, N. O. C. Cezar, R. V. Pedroso, G. Gomes, Adherence, Adhesion, and Dropout Reasons of a Physical Activity Program in a High Social Vulnerability Context, Journal of Physical Activity and Health, 16 (2019) 149-156. [DOI] [PubMed]

[15] P.G. Rossi, L. Carnaz, W.L. Bertollo, A.C.M. Takahashi, Causes of drop out from a physical exercise supervised program specific to older adults, Fisioterapia em Movimento, (2018) [DOI] [PubMed]

[16] C. M. de Liz, A. Andrade, Análise qualitativa dos motivos de adesão e desistência da musculação em academias, Revista Brasileira de Ciências do Esporte, 38 (2016) 267-274. [DOI]

[17] A. V. Silva Filho, C. A. da Silva, A. L. de Paula Rodrigues, Aspectos motivacionais envolvidos na prática regular de treinamento personalizado em academias de Fortaleza-CE, RBPFEX-Revista Brasileira de Prescrição e Fisiologia do Exercício, 13 (2019) 971-981.
[18] M. L. Gonçalves, C. C. F. Bicalho, F. Noce, Analysis of the perception of quality of life in bodybuilding practitioners of a social project, Arquivos de Ciências do Esporte, 7 (2019) 114118.

[19] V. La Fauci, R. Squeri, P. Spataro, C. Genovese, N. Laudani, V. Alessi, Young people, young adults and binge drinking, Journal of preventive medicine and hygiene, 60 (2019) 376-385. [DOI]

[20] P. Latino-Martel, V. Cottet, N. Druesne-Pecollo, F. H. Pierre, M. Touillaud, M. Touvier, M.P. Vasson, M. Deschasaux, J.L. Merdy, E. Barrandon, R. Ancelling, Alcoholic beverages, obesity, physical activity and other nutritional factors, and cancer risk: a review of the evidence, Critical reviews in oncology/hematology, 99 (2016) 308-323. [DOI]

[21] A. M. D. S. Gonçalves, M. Wernet, C. D. S. C. D. Costa, , F. J. G. D. Silva Júnior, A. A. M. D.Moura, S. C. Pillon, Uso de alcohol, tabaco y marihuana: repercusiones en la calidad de vida de los estudiantes, Escola Anna Nery, 24 (2020) 1-7. [DOI]

\section{Funding}

No funding was received for conducting this study.

Does this article screened for similarity? Yes.

\section{Conflict of interest}

The authors have no conflicts of interest to declare that they are relevant to the content of this article.

About The License

(C) The Author(s) 2021. The text of this article is open access and licensed under a Creative Commons Attribution 4.0 International License 